\title{
Antimicrobial activity of customary medicinal plants of the Yaegl Aboriginal community of northern New South Wales, Australia: a preliminary study
}

Joanne Packer ${ }^{1}$, Tarannum Naz ${ }^{1}$, Yaegl Community Elders, David Harrington ${ }^{1}$, Joanne F Jamie ${ }^{1}$ and Subramanyam R Vemulpad ${ }^{1 *}$

\begin{abstract}
Background: This study is a collaboration between Macquarie University researchers and the Yaegl Aboriginal Community of northern NSW, Australia to investigate the antimicrobial potential of plants used in the topical treatment of wounds, sores and skin infections. Based on previously documented medicinal applications, aqueous and aqueous ethanolic extracts of Alocasia brisbanensis, Canavalia rosea, Corymbia intermedia, Hibbertia scandens, Ipomoea brasiliensis, Lophostemon suaveolens and Syncarpia glomulifera and the aqueous extracts of Smilax australis and Smilax glyciphylla were tested against common wound pathogens, including antibiotic resistant bacterial strains.

Methods: Plant material was prepared as aqueous extractions modelled on customary preparations and using $80 \%$ aqueous ethanol. Extracts were assayed against a selection of clinically relevant Gram positive (Streptococcus pyogenes and sensitive and resistant strains of Staphylococcus aureus) and Gram negative (Pseudomonas aeruginosa, Escherichia coli and Salmonella typhimurium) bacteria and a fungus (Candida albicans) using disc diffusion and MTT microdilution methods. Viability of treated microorganisms was determined by subculturing from microdilution assays.

Results: The extracts of Corymbia intermedia, Lophostemon suaveolens and Syncarpia glomulifera had promising levels of antimicrobial activity (MIC 31-1,000 $\mu \mathrm{g} / \mathrm{mL}$ ) against both antibiotic sensitive and resistant Staphylococcus aureus as well as the fungus Candida albicans (clinical isolate).

Conclusion: Aqueous and $80 \%$ aqueous ethanolic extracts of Lophostemon suaveolens, Corymbia intermedia and Syncarpia glomulifera exhibited promising levels of antimicrobial activity against a range of both antibiotic sensitive and resistant strains of microorganisms. This is the first report of antimicrobial activities for $C$. intermedia and $L$. suaveolens and the leaves of S. glomulifera. This study demonstrates the value of customary knowledge in the identification of new sources of antimicrobial treatments.
\end{abstract}

Keywords: Antimicrobials, Multidrug resistant, Wound healing, Traditional medicine, Ethnobotany

\section{Background}

Australian Aboriginal people have over 40,000 years of knowledge of flora and fauna as sources of food,

\footnotetext{
${ }^{*}$ Correspondence: subramanyam.vemulpad@mq.edu.au

${ }^{1}$ Indigenous Bioresources Research Group, Faculty of Science and Engineering, Macquarie University, North Ryde, Sydney 2109, Australia

Full list of author information is available at the end of the article
}

healing agents and other resources. Studies of customary (traditional and contemporary) medicinal plant preparations, especially in recent years, have revealed interesting medicinal properties and valuable biologically active compounds [1]. Australian Aboriginal medicinal flora have had limited biological screening studies aligned with their medicinal uses. Furthermore, the knowledge of their medicinal uses is quickly disappearing [2], particularly in some regions of the country, such as 
the southern states of Australia. Assessment of the bioactive potential of these plants with long historical use may support their wider application and also provide a source for safe, accessible alternative medicines and leads for the discovery of new drug-like molecules [3].

The ongoing crisis of antimicrobial resistance [4] calls for the investigation of novel sources of antimicrobials. Working with Indigenous communities who have been using natural remedies over the centuries can provide novel sources of antimicrobial therapies and/or lead compounds for the development of new medicines [3].

Discussions with Elders of the Yaegl Aboriginal community of New South Wales, Australia on their customary (traditional and contemporary medicines) identified plants used in the topical treatment of conditions of a microbial aetiology [5]. These included Alocasia brisbanensis for burns and boils, cuts, sores and open wounds; Lophostemon suaveolens, Smilax australis, Smilax glyciphylla and Syncarpia glomulifera for antiseptic purposes; Canavalia rosea for boils and sores, Corymbia intermedia for the treatment of wounds; Hibbertia scandens for sores and rashes; and Ipomoea brasiliensis as a poultice for boils.

There has been little investigation into these plants identified by the Yaegl community for their antimicrobial potential. This study looks into the antimicrobial activity of these plants against eight pathogenic organisms commonly implicated in wounds, sores and skin infections.

\section{Methods}

\section{Ethics protocol}

This research was approved by the Human Ethics Committee at Macquarie University, (HE27 JUL2007-R05356 and 5201200763). It was conducted under the framework of best ethical practice, working in partnerships with Indigenous people $[6,7]$ and was governed by a cooperative research agreement with the Yaegl community [8]. The choice of plants and the biological testing to be undertaken were determined in consultation with the Yaegl community through the Yaegl Local Aboriginal Land Council as the appropriate authorising body. The proposed methods and workflow were discussed before work commenced, and the results of the screening were presented back to the Yaegl community in the form of regular reports and presentations. The regular contact with the community during all phases of this research project ensured that the progress of the project remained in accordance with the requirements of the community and academics.

\section{Plant collection and identification}

Plants were collected in March 2011 after being located and identified with the assistance of the knowledge holders of the Yaegl community. Plant identification was confirmed by and voucher specimens deposited at the Herbarium of the Royal Botanic Gardens of NSW or the Macquarie University Herbarium [registered with the Index Herbariorum, New York Botanic Gardens (http:// sciweb.nybg.org/science2/IndexHerbariorum.asp)], with the prefix MQU.

For all plants the material used was leaves, except for I. brasiliensis where the stem and leaves were used. Plant material was weighed and washed twice with water to remove surface contaminants and extraneous material. Approximately $50 \mathrm{~g}$ of fresh plant material for each extraction method was collected (except for $S$. australis and S. glyciphylla, where $10 \mathrm{~g}$ was collected for the aqueous extraction only, due to inadequate availability of the plant material in the area).

\section{Chemicals}

Unless otherwise indicated, all chemicals were sourced from Sigma Aldrich, St Louis, USA. All media listed below were sourced from Bacto Laboratories Pty Ltd, Australia and prepared as per the manufacturer's instructions.

\section{Extraction of plant material}

Aqueous extraction of samples for antimicrobial screening Plant material was, where possible, prepared in a way consistent with the preparation methods described by the Yaegl Elders [5] within $48 \mathrm{~h}$ of collection. In the case of pink bloodwood (C. intermedia) and apple gum (L. suaveolens or S. glomulifera), sap or latex while customarily used. Due to the risk of considerable damage to the tree, sap or latex was not collected and the Elders requested the leaves be collected and tested as an accessible and sustainable option. For C. rosea and H. scandens, the specifics of the preparation method could not be recalled by the knowledge holders.

Aqueous extractions were prepared as either a decoction or an infusion as described below.

Decoction (D): Plant material was pounded and boiled in $10 \times(w / v)$ tap water for $10 \mathrm{~min}$, before being left to steep and cool (covered, for approximately $60 \mathrm{~min}$ ). The decoction was filtered and the filtrate collected.

Hot infusion (I): Freshly boiled water was poured over roughly chopped or torn plant material $(10 \times w / v)$. The infusion was covered and allowed to steep for $2 \mathrm{~h}$. The infusion was filtered and the filtrate collected.

Cold infusion (CI): Plant material was roughly chopped or torn and submerged in $10 \times(w / v)$ water at room temperature. The infusion was shaken gently for $24 \mathrm{~h}$, the mixture was vacuum filtered and the solid was shaken with fresh water $(10 \times w / v)$ for an additional $24 \mathrm{~h}$ and filtered. The filtrates were pooled. 
All crude aqueous extracts were dried by rotary evaporation (Büchi, Germany) at reduced pressure at approximately $50^{\circ} \mathrm{C}$, followed by freeze drying (Labconco freeze dryer, USA). Extracts were stored at $-20^{\circ} \mathrm{C}$.

\section{Aqueous ethanolic extraction of samples for antimicrobial screening}

Fresh plant material was ground to a coarse powder using a coffee grinder (IKA ${ }^{\circ}$ A11 Basic, Selangor, Malaysia) and shaken in $10 \times w / v$ of $80 \% v / v$ aqueous ethanol at room temperature [9] for approximately $48 \mathrm{~h}$. The mixture was filtered and the solid shaken with fresh $80 \% \mathrm{v} / \mathrm{v}$ aqueous ethanol $(10 \times w / v)$ for an additional $48 \mathrm{~h}$, and the filtrates pooled. The ethanolic portion was removed by rotary evaporation under reduced pressure at a low heat $\left(<40^{\circ} \mathrm{C}\right)$, leaving the water portion, which was freeze dried and stored at $-20^{\circ} \mathrm{C}$.

\section{Microbial strains}

All extracts were initially screened against one Gram positive (Staphylococcus aureus ATCC 29213) and two Gram negative (Escherichia coli $\beta$-lactamase negative ATCC 25922 and Pseudomonas aeruginosa ATCC 27853) bacterial strains, representing common pathogens associated with wounds, sores and skin infections $[10,11]$. Selected extracts were also assayed against a broader range of microorganisms including: Streptococcus pyogenes-Group A, clinical isolate; Salmonella typhimurium-Group B, clinical isolate; resistant $S$. aureus strains (ATCC BAA 1026 community acquired methicillin resistant (CMRSA); wild multidrug resistant MRSA clinical isolate) and a yeast (Candida albicans-clinical isolate).

All microbial strains were kindly provided by $\mathrm{Dr}$ John Merlino (Department of Microbiology, Concord Hospital, Sydney) and the work was approved by the Macquarie University Biosafety Committee (Approval Reference 08/06/LAB, JOP250512BHA, TAN180512BHA). Müller Hinton II (MH) broth was used as the liquid medium for all bacteria; $\mathrm{MH}$ agar was used for the growth of E. coli, S. aureus, S. typhimurium and $P$. aeruginosa strains; horse blood agar (Edwards Instruments, Australia), was used for S. pyogenes. Potato dextrose agar (PDA, Oxoid, Basingstoke, UK) and Difco Sabouraud dextrose broth (SAB) were used for C. albicans. Gentamycin was used as the antibiotic control for the sensitive strains of S. aureus, E. coli, S. typhimurium and $P$. aeruginosa, vancomycin for the resistant strains of S. aureus and penicillin G for S. pyogenes (all antibiotics were supplied by Amresco, Ohio, USA). Fluconazole (MP Biomedicals, Ohio, USA) or miconazole (MP Biomedicals, LLC, France) was used as the antifungal control for the assays involving C. albicans.

\section{Disc diffusion assay}

Dried plant material was dissolved in DMSO at $50 \mathrm{mg} /$ $\mathrm{mL}$. Antibiotic controls were prepared in broth at a concentration of $0.1 \mathrm{mg} / \mathrm{mL}$. Sterile paper discs $(\emptyset 6 \mathrm{~mm}$, Whatman, Maidstone, UK) were impregnated with $2 \times 10 \mu \mathrm{L}$ of plant extract ( $1 \mathrm{mg} /$ disc) or antibiotic control $(2 \mu \mathrm{g} /$ disc $)$ and air-dried. $20 \mu \mathrm{L}$ DMSO impregnated discs were included as a negative control. Discs were placed on appropriate agar plates (horse blood agar for S. pyogenes, potato dextrose agar for C. albicans or $\mathrm{MH}$ agar for other microorganisms), inoculated with broth cultures at $\mathrm{A}_{600}=0.08$ (bacteria: $10^{7}-10^{8} \mathrm{cfu} / \mathrm{mL}, C$. albicans: $10^{5} \mathrm{cfu} / \mathrm{mL}$ ) and incubated at $37^{\circ} \mathrm{C}$ for $18-24 \mathrm{~h}$ $\left(30^{\circ} \mathrm{C}\right.$ for $48 \mathrm{~h}$ for C. albicans). The antimicrobial activity was measured as the zone of inhibition from the edge of the disc. Each sample and microbial combination was tested as at least four replicates.

\section{MTT microdilution assay}

The assay was performed as outlined by Steenkamp et al., with minor modifications [12]. Plant extracts were prepared at $10 \mathrm{mg} / \mathrm{mL}$ in $\mathrm{MH}$ broth/20\% DMSO (or $\mathrm{SAB} / 20 \%$ DMSO for $C$. albicans) and serially diluted to give $20 \mu \mathrm{L}$ final plant sample concentrations of $2-1,000 \mu \mathrm{g} / \mathrm{mL}(0.02-10 \mu \mathrm{g} / \mathrm{mL}$ of antibiotic control) in 96-well clear bottom microtitre plates. Test samples were inoculated with $175 \mu \mathrm{L}$ of microbial culture $\left(\mathrm{A}_{600}=0.08\right.$ diluted $1 / 100$ in $\mathrm{MH}$ broth $)$; a sterile broth control was included. The plates were incubated at $37^{\circ} \mathrm{C}$ for $18 \mathrm{~h}\left(30^{\circ} \mathrm{C}\right.$ for C. albicans $), 5 \mu \mathrm{L}$ of a sterile methanolic solution $(5 \mathrm{mg} / \mathrm{mL})$ of MTT was added to each well and incubated at $37^{\circ} \mathrm{C}$ for $60 \mathrm{~min}$. The MIC was the lowest concentration of test material in which no growth (as measured by no blue colour) was observed [13].

\section{Microbial viability determination}

Plant extracts with antimicrobial activity (Table 1), as determined by the MTT microdilution assay, were assessed for their microbicidal/static nature by subculturing onto fresh agar plates after the assay [14]. Subcultures not producing colonies were deemed to have been affected by the plant extract by a microbicidal mechanism. The minimum microbicidal concentration was defined as the concentration of the plant extract in the last well showing no further microbial growth on subculture.

\section{Results}

Aqueous or $80 \%$ aqueous ethanolic extracts from nine plants used by the Yaegl community were initially tested against the Gram positive and Gram negative antibiotic sensitive bacteria, S. aureus (ATCC 29213), E. coli ( $\beta$-lactamase negative, ATCC 25922) and $P$. aeruginosa 
Table 1 Initial screening for antimicrobial activity of extracts of plants used customarily to treat skin conditions

\begin{tabular}{|c|c|c|c|c|c|}
\hline \multirow[t]{3}{*}{ Plant $^{\text {a }}$ (voucher number) } & \multirow[t]{3}{*}{ Extract $^{b}$} & \multicolumn{2}{|c|}{$\begin{array}{l}\text { Pseudomonas aeruginosa } \\
\text { (ATCC 27853) }\end{array}$} & \multicolumn{2}{|c|}{$\begin{array}{l}\text { Staphylococcus aureus } \\
\text { (ATCC 29213) }\end{array}$} \\
\hline & & Disc diffusion ${ }^{c}$ & $\mathrm{MTT}^{\mathrm{d}}$ & Disc diffusion ${ }^{c}$ & $\mathrm{MTT}^{\mathrm{d}}$ \\
\hline & & Average (range) & $\begin{array}{l}\text { MIC median } \\
\text { (range) }\end{array}$ & Average (range) & $\begin{array}{l}\text { MIC median } \\
\text { (range) }\end{array}$ \\
\hline \multicolumn{6}{|l|}{ Apple gum } \\
\hline \multirow{2}{*}{$\begin{array}{l}\text { Lophostemon suaveolens (Sol. ex Gaertn.) Peter G. } \\
\text { Wilson \& J.T. Waterh (MQ 73008908) }\end{array}$} & $\mathrm{H}_{2} \mathrm{O}(\mathrm{I})$ & na & na & $2(1-3)$ & $188(125-250)$ \\
\hline & $\mathrm{EtOH}$ & na & na & $3(2.5-3.5)$ & $93(63-125)$ \\
\hline \multirow{2}{*}{$\begin{array}{l}\text { Syncarpia glomulifera } \\
\text { subsp. glomulifera (Sm.) Nied. (MQ 73009066) }\end{array}$} & $\mathrm{H}_{2} \mathrm{O}(\mathrm{I})$ & $5.5(0-10)$ & na & $6.5(5-10)$ & $300(250-500)$ \\
\hline & $\mathrm{EtOH}$ & na & na & $3(3-6)$ & $63(31-63)$ \\
\hline \multicolumn{6}{|l|}{ Beach morning glory } \\
\hline \multirow[t]{2}{*}{ Ipomoea brasiliensis (L.) Sweet (MQ 73007958)A } & $\mathrm{H}_{2} \mathrm{O}(\mathrm{D})$ & na & na & na & na \\
\hline & $\mathrm{EtOH}$ & na & na & na & na \\
\hline \multicolumn{6}{|l|}{ Bloodwood } \\
\hline \multirow{2}{*}{$\begin{array}{l}\text { Corymbia intermedia (R.T. Baker) K.D. Hill \& L.A.S. John- } \\
\text { son (NSW 792670) }\end{array}$} & $\mathrm{H}_{2} \mathrm{O}(\mathrm{l})$ & $1(1)$ & na & $2(1-3.5)$ & $250(250-500)$ \\
\hline & $\mathrm{EtOH}$ & na & na & $2.5(2-4)$ & $299(174-500)$ \\
\hline \multicolumn{6}{|l|}{ Coastal jackbean } \\
\hline \multirow[t]{2}{*}{ Canavalia rosea (Sw.) DC. (MQ 73008909) } & $\mathrm{H}_{2} \mathrm{O}(\mathrm{D})$ & na & na & na & na \\
\hline & $\mathrm{EtOH}$ & na & na & na & na \\
\hline \multicolumn{6}{|l|}{ Cunjevoi } \\
\hline \multirow[t]{2}{*}{ Alocasia brisbanensis Domin (MQ 73008737) } & $\mathrm{H}_{2} \mathrm{O}(\mathrm{D})$ & na & na & na & na \\
\hline & $\mathrm{EtOH}$ & na & na & na & na \\
\hline \multicolumn{6}{|l|}{ Sarsaparilla } \\
\hline Smilax australis R.Br. (wide leaf) (NSW 792674) & $\mathrm{H}_{2} \mathrm{O}(\mathrm{I})$ & na & na & na & na \\
\hline Smilax glyciphylla Sm. (narrow leaf) (NSW 792380) & $\mathrm{H}_{2} \mathrm{O}(\mathrm{I})$ & na & na & na & na \\
\hline \multicolumn{6}{|l|}{ Yellowvine } \\
\hline \multirow[t]{2}{*}{ Hibbertia scandens (Willd.) Gilg (MQ 73008905) } & $\mathrm{H}_{2} \mathrm{O}(\mathrm{D})$ & na & na & na & na \\
\hline & $\mathrm{EtOH}$ & na & na & na & na \\
\hline \multicolumn{2}{|l|}{ Antibiotic control (Gentamycin) } & $8(8)$ & 1.25 & $8(8)$ & 0.5 \\
\hline \multicolumn{6}{|l|}{ na no activity detected. } \\
\hline \multicolumn{6}{|l|}{ a Leaves of plants used in all cases except where indicated. } \\
\hline \multicolumn{6}{|c|}{ b Extraction method used: $\mathrm{H}_{2} \mathrm{O}$ - based on traditional preparation ( $\mathrm{D}$, decoction; I, infusion; $\mathrm{Cl}$, cold infusion), EtOH—80\% aqueous ethanol. } \\
\hline \multicolumn{6}{|c|}{ c Values given are inhibition in $\mathrm{mm}$ from the edge of the disc; average (range) of 4 replicates. } \\
\hline \multicolumn{6}{|c|}{${ }^{d}$ MIC noted as $\mu \mathrm{g} / \mathrm{mL}$, based on the last dilution of extract not to exhibit yellow-blue colour change in MTT assay; values given are median (range) of four replicates. } \\
\hline
\end{tabular}

(ATCC 27853) using the disc diffusion and MTT assays. The plant extracts showed activity only against $S$. aureus (in both disc diffusion and MTT assays) and $P$. aeruginosa (in disc diffusion assay only). L. suaveolens, C. intermedia and S. glomulifera extracts had the highest levels of antimicrobial activity (Table 1 ).

Antimicrobial activity for mixtures or crude plant extracts of between 0.1 and $1 \mathrm{mg} / \mathrm{mL}$ have been suggested as being appropriate for further investigation [15]. L. suaveolens, C. intermedia and S. glomulifera crude plant extracts were therefore further investigated as they had MIC values $\leq 500 \mu \mathrm{g} / \mathrm{mL}$ (Table 1). These extracts were tested against a broader spectrum of microorganisms viz. Candida albicans, Streptococcus pyogenes, Salmonella typhimurium and resistant strains of S. aureus-multidrug resistant (MDRSA) and community acquired methicillin resistant (CMRSA). Table 2 (and Additional file 1) presents the activities of these extracts. Results for S. typhimurium are not included as no activity was observed with any of the three plants. The $80 \%$ aqueous ethanolic extract of $S$. glomulifera was the most active of the extracts, based on low MIC values $(31 \mu \mathrm{g} /$ $\mathrm{mL}$ ) against the tested bacteria as well as $C$. albicans. The $80 \%$ aqueous ethanolic extracts of both L. suaveolens and S. glomulifera were microbicidal in their activity against the susceptible microorganisms. 


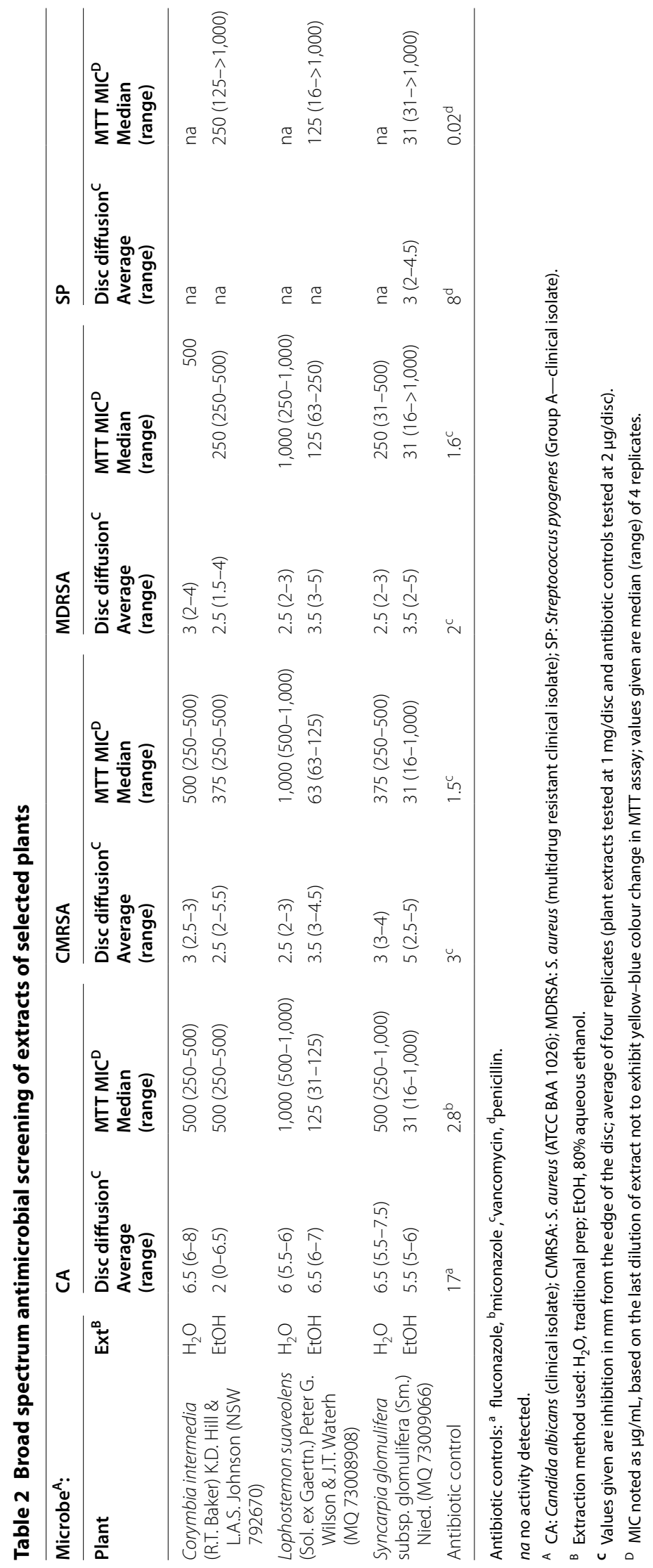




\section{Discussion}

Ethnobotanical studies conducted by us with Yaegl Aboriginal Elders of northern New South Wales, Australia, described the use of Alocasia brisbanensis, Canavalia rosea, Corymbia intermedia, Hibbertia scandens, Ipomoea brasiliensis, Lophostemon suaveolens, Smilax australis, Smilax glyciphylla and Syncarpia glomulifera for the treatment of wounds, sores and skin infections [5]. None of these plants have been investigated for their antimicrobial activity, with the exception of C. rosea [16]. The success of finding antimicrobial activity and bioactive compounds of medicinal value from traditional/customary medicines [3], prompted the investigation of these plants.

The plants were extracted with water to mimic the common customary practice of the community and/or with $80 \%$ aqueous ethanol, as a standard natural products research method [9]. The plant parts extracted were the same as those used by the Yaegl community, except for bloodwood (C. intermedia) and apple gum (L. suaveolens or S. glomulifera), where customarily the sap or latex was used in the treatment of wounds. However, as sap or latex were not readily accessible, we tested the leaves at the request of the Yaegl Elders.

The microorganisms selected for the assays are commonly implicated in wounds, sores and skin infections [11]. The two assay methods were chosen as they complement each other in that the disc diffusion assay is simple but not always appropriate for non-polar and large molecules [17] and the more sensitive, versatile and quantitative MTT microdilution assay can have interference with the colour and redox activity of plant extracts.

The extracts of C. intermedia, L. suaveolens and S. glomulifera had reasonable levels of antimicrobial activity (MIC $0.1-1 \mathrm{mg} / \mathrm{mL}$; [15]) against antibiotic sensitive and resistant Staphylococcus aureus as well as the fungus Candida albicans (clinical isolate). Although antibacterial activity of the ethanolic extract of $C$. rosea leaves has been previously reported against S. aureus, albeit at a low level [16], no antibacterial activity was seen in this study, possibly due to the different bacterial strains and assay conditions used.

The $80 \%$ aqueous ethanolic extracts of C. intermedia, L. suaveolens and S. glomulifera were substantially more active than the aqueous extracts. This indicates that the antimicrobial components in these plants were more easily extractable in $80 \%$ aqueous ethanol. S. glomulifera was the most active of the extracts (Table 2). The $80 \%$ aqueous ethanolic extracts of both $L$. suaveolens and $S$. glomulifera were microbicidal in their activity against the susceptible microorganisms.

Sap from bloodwood (C. intermedia) has been used by the Yaegl community in the treatment of wounds [5]. No chemical or biological studies have been reported for $C$. intermedia. Milky sap and ash from the bark of the apple gum (Lophostemon suaveolens or Syncarpia glomulifera) have been used as antiseptics by the Yaegl community [5]. These two plants are sometimes interchangeably used due to their similar morphology.

No antimicrobial activity studies have been reported for $L$. suaveolens or the leaves of S. glomulifera. However, both plants have been found to contain the following compounds that have been independently reported for antimicrobial activity [18-22]. Leaves of L. suaveolens have been found to contain $\alpha$-pinene, $\beta$-caryophyllene, aromadendrene, globulol and spathulenol [23], which have been independently reported for antimicrobial activity. The leaves of $S$. glomulifera also contain $\alpha$-pinene, aromadendrene and globulol [24]. Eucalyptin, which has been reported to be antibacterial, has been found in the leaf wax of S. glomulifera [25]. Additionally, S. glomulifera bark has been reported to be antibacterial and to contain the antibacterial compounds betulinic acid, oleanolic acid-3-acetate and ursolic acid-3-acetate [26].

This is the first report of antimicrobial activities for $C$. intermedia and L. suaveolens and the leaves of S. glomulifera. These results warrant further investigation of the active ingredients of these medicinal plants.

\section{Conclusion}

$80 \%$ aqueous ethanolic extracts of Lophostemon suaveolens and Syncarpia glomulifera showed microbicidal activity at concentrations of $<200 \mu \mathrm{g} / \mathrm{mL}$ against $C$. albicans and both sensitive and resistant strains of $S$. aureus. Aqueous extracts of L. suaveolens and S. glomulifera and aqueous and ethanolic extracts of Corymbia intermedia exhibited microbicidal activity against a range of both antibiotic sensitive and resistant strains of microorganisms at levels below $1,000 \mu \mathrm{g} / \mathrm{mL}$. This is the first report of antimicrobial activities for $C$. intermedia and L. suaveolens and the leaves of S. glomulifera. This study demonstrates the value of customary knowledge in the identification of new sources of antimicrobial treatments.

\section{Additional file}

Additional file 1. Picture showing typical results of the disc diffusion assay.

\section{Authors' contribution}

JP and TN carried out the extractions and biological assays, wrote the paper and evaluated the data. YCE provided the valuable customary knowledge and input to the research directions. DH collected the plant samples and contributed to the literature search. JJ and SV initiated and directed the research. All authors read and approved the final manuscript.

\section{Author details}

${ }^{1}$ Indigenous Bioresources Research Group, Faculty of Science and Engineering, Macquarie University, North Ryde, Sydney 2109, Australia. ${ }^{2}$ Yaegl Local Aboriginal Land Council, Jubilee St, Hillcrest, Maclean, NSW 2463, Australia. 


\section{Acknowledgements}

The authors thank the Yaegl Elders for sharing their knowledge on behalf of the Yaegl community, in particular Ronald Heron, Jessie Randall, Della Walker, Lillian Williams, Judith Breckenridge, Carmel Charlton, Darren King, Rosemarie Vesper, Muriel Burns, Beatrice Heron, Owen Kapeen, Thelma Kapeen, Eileen McLeay, Glenda McPhail, Lester Mercy, Lenore Parker, Irene Randall, Kevin Randall and Lenny Waters. The authors acknowledge Elders who have passed away and are grateful to their family for permitting the inclusion of their knowledge. We are grateful to Noeline Kapeen and Eileen McLeay from the Yaegl Local Aboriginal Land Council and Michael and Deidre Randall for assisting in the initiation and execution of the project. This project would not have been possible without the financial support provided by Macquarie University in the form of PhD scholarships to the authors Joanne Packer and Tarannum Naz and funding from the National Health and Medical Research Council (NH\&MRC \#488504 and \#1028092).

\section{Compliance with ethical guidelines}

\section{Competing interests}

The authors declare that they have no competing interests. There is no financial relationship with other people or organisations in implementation, analysis or financing of this study.

Received: 13 May 2015 Accepted: 22 June 2015

Published online: 30 June 2015

\section{References}

1. Pennacchio M, Kemp AS, Taylor RP, Wickens KM, Kienow L (2005) Interesting biological activities from plants traditionally used by native Australians. J Ethnopharmacol 96(3):597-601

2. Morgan G (2006) Unsettled places: Aboriginal people and urbanisation in New South Wales. Wakefield Press Pvt Limited, Adelaide

3. Cragg GM, Newman DJ (2013) Natural products: a continuing source of novel drug leads. Biochimica et Biophysica Acta General Subjects 1830(6):3670-3695

4. Moir DT, Opperman TJ, Butler MM, Bowlin TL (2012) New classes of antibiotics. Curr Opin Pharmacol 12(5):535-544

5. Packer J, Brouwer N, Harrington D, Gaikwad J, Heron R, Yaegl CE et al (2012) An ethnobotanical study of medicinal plants used by the Yaegl Aboriginal community in northern New South Wales, Australia. J Ethnopharmacol 139:244-255

6. UNESCO (2008) Links between biological and cultural diversity-concepts, methods and experiences. In: Persic A, Martin G (eds) International Workshop Report. UNESCO, Paris

7. NHMRC (2003) Values and ethics: guidelines for ethical conduct in aboriginal and Torres Strait Islander health research. National Health and Medical Research Council. Commonwealth of Australia, Canberra

8. Brouwer N, Liu Q, Harrington D, Kohen J, Vemulpad S, Jamie J et al (2005) An ethnopharmacological study of medicinal plants in New South Wales. Molecules 10(10):1252-1262
9. Houghton PJ, Raman A (1998) Laboratory handbook for the fractionation of natural extracts. Chapman \& Hall, London

10. Currie BJ, Carapetis JR (2000) Skin infections and infestations in Aboriginal communities in northern Australia. Australas J Dermatol 41(3):139-143

11. Stulberg DL, Penrod MA, Blatny RA (2002) Common bacterial skin infections. Am Fam Physician 66(1):119-128

12. Steenkamp V, Mathivha E, Gouws MC, van Rensburg CEJ (2004) Studies on antibacterial, antioxidant and fibroblast growth stimulation of wound healing remedies from South Africa. J Ethnopharmacol 95(2-3):353-357

13. Appendino G, Gibbons S, Giana A, Pagani A, Grassi G, Stavri M et al (2008) Antibacterial cannabinoids from Cannabis sativa: a structure-activity study. J Nat Prod 71(8):1427-1430

14. Karaman I, Sahin F, Güllüce $M$, Ögütçü H, Sengül M, Adlgüzel A (2003) Antimicrobial activity of aqueous and methanol extracts of Juniperus oxycedrus L. J Ethnopharmacol 85(2-3):231-235

15. Rios JL, Recio MC (2005) Medicinal plants and antimicrobial activity. J Ethnopharmacol 100(1):80-84

16. Prabhu S, Raj LJM, Britto SJ, Senthilkumar SR (2010) Antibacterial activity and preliminary phytochemical analysis of leaf extract of Canavalia rosea (Sw.) DC (Beach Bean). Int J Res Pharm Sci 1(4):428-434

17. Barry A, Thornsberry C (1991) Susceptibility tests: diffusion test procedures. In: Balows A, Hausler WJ, Hermann K, Isenberg H, Shadomy H (eds) Manual of clinical microbiology, 5th edn. American Society for Microbiology, Washington, DC, pp 1117-1125

18. Dorman H, Deans S (2000) Antimicrobial agents from plants: antibacterial activity of plant volatile oils. J Appl Microbiol 88(2):308-316

19. Oztürk M, Duru M, Aydoğmuş-Oztürk F, Harmandar M, Mahlicli M, Kolak $U$ et al (2009) GC-MS analysis and antimicrobial activity of essential oil of Stachys cretica subsp. smyrnaea. Nat Product Commun 4(1):109-114

20. Tan M, Zhou L, Huang Y, Wang Y, Hao X, Wang J (2008) Antimicrobial activity of globulol isolated from the fruits of Eucalyptus globulus Labill. Nat Prod Res 22(7):569-575

21. Bougatsos C, Ngassapa O, Runyoro DK, Chinou IB (2004) Chemical composition and in vitro antimicrobial activity of the essential oils of two Helichrysum species from Tanzania. Zeitschrift fur Naturforschung C (J Biosci) 59(5-6):368-372

22. Takahashi T, Kokubo R, Sakaino M (2004) Antimicrobial activities of eucalyptus leaf extracts and flavonoids from Eucalyptus maculata. Lett Appl Microbiol 39(1):60-64

23. Brophy JJ, Goldsack RJ, Forster PI (2000) Essential oils of the genus Lophostemon (Myrtaceae). Flavour Fragr J 15(1):17-20

24. Brophy JJ, Goldsack RJ, Bean AR, Forster PI, Fookes CJR (1996) The leaf essential oils of the genus Syncarpia Ten. (Myrtaceae). Flavour. Fragr J 11(6):361-366

25. Courtney JL, Lassak EV, Speirs GB (1983) Leaf wax constituents of some myrtaceous species. Phytochemistry 22:947-949

26. Setzer WN, Setzer MC, Bates RB, Jackes BR (2000) Biologically active triterpenoids of Syncarpia glomulifera bark extract from Paluma, north Queensland, Australia. Planta Medica 66(2):176-177

\section{Submit your next manuscript to BioMed Central and take full advantage of:}

- Convenient online submission

- Thorough peer review

- No space constraints or color figure charges

- Immediate publication on acceptance

- Inclusion in PubMed, CAS, Scopus and Google Scholar

- Research which is freely available for redistribution 